\title{
EL PROCESO DE DIFUSIÓN DE LA PATATA EN CATALUÑA. UNA REVISIÓN DE LAS TESIS ELITISTAS 0 INSTITUCIONALISTAS ${ }^{1}$
}

\author{
Rosa Congost \\ Centre de Recerca d'Història Rural, Universitat de Girona
}

\begin{abstract}
Resumen. En Cataluña, como en muchas regiones europeas, se halla muy arraigada la idea de que un producto alimentario nuevo, para tener éxito y universalizarse, requiere de la intervención de una institución o de una élite que lo propague entre el conjunto de la población dedicada a la agricultura. A pesar de las escasas noticias empíricas disponibles, la historiografía catalana ha aplicado esta tesis a la difusión de la patata a fines del siglo XVIII y principios del XIX. Sin embargo, la relectura de los testimonios escritos por algunos viajeros y pensadores ilustrados de fines del siglo XVIII y, en especial, los realizados por el médico Juan Francisco Bahí entre 1815 y 1821, que habían servido de base a esta tesis, y el carácter silencioso del proceso real de difusión del tubérculo, sugieren que, a diferencia de lo que habíamos tendido a pensar, el pequeño campesinado pudo jugar un papel más activo y decisivo en ese proceso de difusión.
\end{abstract}

Palabras clave: patata, Cataluña, siglos XVIII y XIX, difusión de cultivos, pequeño campesinado.

ABSTRACT. In Catalonia, as in many European regions, the idea that the successful introduction of a new food product, like any other innovation, requires the intervention of an institution or elite that propagates it among the set of the population is deeply rooted. Catalan historiography has applied this thesis to the dissemination of the potato at the end of the 18th century and the beginning of the 19th century, despite the scant empirical evidence available. However, the rereading of the texts used as the basis for this thesis, the testimonies written by some travelers

Recibido: 2-7-2018 • Aceptado: 4-10-2018 · rosa.congost@udg.edu

Este trabajo se enmarca en el proyecto HAR2014-54891-P, financiado por el Ministerio de Ciencia, Innovación e Universidad. Agradezco a los miembros del proyecto y a los evaluadores anónimos sus comentarios y consideraciones sobre el texto publicado. 
and enlightened thinkers of the late eighteenth century and, in particular, by the physician Juan Francisco Bahí, from 1815 to 1821, as well as the silent character of the actual diffusion process of the tuber, suggest that, unlike what we had tended to think, the small peasantry could have played an important and decisive role in this process.

Key words: potato, Catalonia, $18^{\text {th }}$ and $19^{\text {th }}$ centuries, crop diffusion, smallholders.

ENTENDEMOS por tesis elitistas o institucionalistas aquellas que atribuyen un rol determinante en el desarrollo de un proceso histórico a las élites y a las instituciones. En el caso de los procesos exitosos de difusión de la patata en Europa, este tipo de tesis ha servido para reivindicar la figura de algunos gobernantes y algunos espíritus selectos, que suelen pertenecer a las clases dominantes. A nivel internacional, los casos más paradigmáticos, y no exentos de leyenda, han sido los de Federico II de Prusia y el farmacéutico Antoine Parmentier, en Francia ${ }^{2}$. En líneas generales, el mayor logro de las instituciones o élites protagonistas de este relato - considerado positivo para el conjunto de la historia de la humanidad-, radicó en su capacidad para ayudar a superar los problemas derivados de las reticencias que mostraban unos campesinos ignorantes a la hora de adoptar el nuevo cultivo.

A pesar de lo que acabamos de decir, en casi todos los países donde el tema ha sido investigado, se halla bastante asumido que las patatas fueron consumidas en la mesa de los pobres mucho antes que en la de los ricos, y en muchos de estos países se considera que el proceso que elevó el tubérculo de alimento animal a la categoría de alimento humano se produjo en circunstancias específicas de escasez o miseria, como serían por ejemplo los contextos bélicos (Febvre, 1940; Morineau, 1970; Salaman, 1985). La simple constatación de esas dos circunstancias no solo añade algunos matices a la interpretación clásica sobre el papel de las élites — por ejemplo, enfatizando el espíritu generoso y caritativo que podía haber guiado sus actuaciones, o el papel de algunas instituciones específicas, como el ejército-, sino que sugiere que otra interpretación, es decir, una interpretación no elitista, en la cual los campesinos podrían haber sido menos ignorantes y tener un rol más activo de lo que se había supuesto, también es posible 3 . En este caso, su analfabetismo dejaría de ser una prueba más de

La consideración de Antoine Parmentier como introductor de la patata en Francia es habitual en las enciclopedias y diccionarios vigentes, a pesar de haber sido cuestionado, como mínimo, desde principios del siglo XX, por los estudios especializados. Véase, por ejemplo, Gibault (1912).

3 Enlazaríamos de este modo con la literatura agrarista (en antropología, etnoecología y también en historia), que en las últimas décadas ha otorgado un papel principal a las iniciativas campesinas en los procesos de innovación y cambio. El enfoque no es nuevo, como lo evidencian los trabajos de Ernest Labrousse (1944) y Pierre Vilar (1962) sobre la importancia de los pequeños productores en 
su ignorancia y pasaría a ser entonces un dato importante a tener en cuenta la hora de señalar las dificultades para conocer la realidad de sus saberes en materia agraria.

En este trabajo, nos serviremos del ejemplo catalán para desarrollar esta hipótesis de trabajo ${ }^{4}$. En primer lugar, recordaremos las evidencias históricas que han permitido situar los orígenes del cultivo de la patata en el último tercio del siglo XVIII y su indudable consolidación a mediados del siglo XIX, ya en pleno proceso de industrialización. La cronología no es excesivamente tardía, sobre todo si tenemos en cuenta que estamos hablando de una región mediterránea (Gentilcore, 2012; Demo, Ferrari, 2015). A continuación, examinaremos el peso de las ideas elitistas en las interpretaciones especializadas sobre el proceso de difusión del tubérculo en Cataluña. Podemos avanzar aquí que lo más relevante de este apartado será la relectura e interpretación de las aportaciones contenidas en los artículos de Joan Francisco Bahí, escritos poco después de la Guerra de la Independencia. En la tercera parte, esbozaremos una respuesta a la pregunta que ha inspirado este trabajo y que la citada relectura de los textos de Bahí no ha hecho sino estimular: ¿qué papel pudieron desempeñar los campesinos, y especialmente los más humildes, en la expansión de la patata en Cataluña?

\section{Cronología del cultivo de la patata en Cataluña}

Las noticias sobre la presencia de las patatas en Cataluña se concentran en dos etapas igualmente interesantes, ya que nos permiten conocer los orígenes del proceso y la etapa de su consolidación definitiva como cultivo alimentario. Para documentar los orígenes, son especialmente útiles los relatos de algunos viajeros y eruditos del último tercio del siglo XVIII, mientras que en las décadas centrales del siglo XIX proliferan

el proceso de especialización vitícola que conocieron muchas regiones europeas en el siglo XVIII. Sobre la revolución agrícola inglesa, véase Allen (2004) y también Broad (2013).

4 Pero las tesis que aquí se discuten no son exclusivas del área catalana. Para el conjunto de España, la referencia bibliográfica obligada, que incluía datos sobre Galicia, Asturias, Cantabria, País Vasco, Cuenca del Duero, El Valle del Ebro, La Mancha, Andalucia y Valencia, y no sobre Cataluña, fue el trabajo de Juan Piqueras (1992), sobre el papel de las Sociedades Economías de Amigos del País y los curas rurales. Puede ser interesante constatar que este autor señala la nula atención que las Sociedades Económicas de Amigos del País de Santiago y Lugo prestaron al cultivo de la patata; ello encajaría con el conjunto de estudios que han señalado el papel de los campesinos pobres, enfrentados por este motivo a rentistas y a diezmadores, en el proceso de difusión del tubérculo del último tercio del siglo XVIII en Galicia, como puede verse en las síntesis ofrecidas por Hortensio Sobrado (1996; 2016). Por otro lado, la tesis que atribuye un papel motor a las élites en la difusión del cultivo de las patatas mantiene un peso historiográfico importante en algunas investigaciones recientes, como las referidas al País Vasco; vease Palanca (2012). Como ejemplo de la vigencia de las tesis elitistas en el conjunto de Europa, cabe citar el trabajo reciente de Earle (2018).

5 Para la función que la patata pudo jugar en el sistema agrario catalán y sus posibles conexiones con otros procesos relevantes, como el proceso de especialización víticola catalán, temas que no serán tratados aquí, véase Congost (1989). 
en cambio los testimonios, de distinta naturaleza, que certifican su asentamiento y difusión como alimento humano.

\section{a) Evidencias sobre la producción y el consumo de patatas a finales del siglo XVIII}

En el memorial para elaboración del pan con patatas presentado en 1772, Jaume Oliveras explicaba que el tubérculo había empezado a cultivarse en los alrededores de la ciudad de Girona y que algunas veces podían comprarse en el mercado, si bien su producción era aún escasa. Aunque la prueba más evidente de que todavía no se habían incorporado a la dieta regular de los pobres de la ciudad la encontramos en 1788 en el apartado «De la comida que debe darse á los del Hospicio», del reglamento del recién inaugurado Hospicio de Girona, el cual nos informa de una manera detallada sobre la dieta que se les daba y donde no figura la patata ${ }^{6}$.

Todas las evidencias recogidas sitúan el cultivo y consumo de patatas en las áreas de montaña, lo que en principio parecería negar cualquier relación complementaria, en esta primera fase de expansión, con el proceso de especialización vitícola (Duran, 1997; Pérez Samper, 2008; Fàbrega, 2017). Y, en particular, destacan las noticias relativas al Valle de Arán. En 1780, en el Discurso sobre la Agricultura, su autor, supuestamente Jaume Caresmar, señalaba la importancia del tubérculo en el valle con estas palabras: «se cogen batatas bastas, que llaman truas, y es de lo que más abunda y con que se mantiene la mayor parte de las gentes, no obstante que algunas veces les causan enfermedades» (Caresmar, 1780, p. 318). En 1787, el agrónomo inglés Arthur Young constató que en aquella comarca se cultivaban más patatas que al otro lado de la frontera, si bien las consideraba ante todo como alimento para los cerdos, al mismo tiempo que, afirmaba, las vacas aprovechaban sus hojas ${ }^{7}$. Al atravesar el valle, el viajero Francisco de Zamora anotó que en él se cultivaban y conocían las llamadas «criadillas de tierra» (Zamora, 1973). Y gracias a las respuestas a su cuestionario, sabemos que también se comían en Vilar, donde se cultivaba «una especie de patatas que llaman trumfats, que se han introducido de esta por la Francia hace 40 años, y se crian dentro de la tierra como los nabos, lo comen personas y bestias». La respuesta de Vielha decía por su parte que «hay otra especie de fruto (de cuio principio no acuerdamos, por ser de edad de 27 años) casi la misma especie que llaman batatas en Castilla; se cogen unas mil quarteras cada año, sirven para engordar los cerdos y

Arxiu Històric de Girona, Reial Hospici, Reglamento, 1788.

Sobre la procedencia de los tubérculos los viajeros aportan pocas noticias. Arthur Young explica que, al interesarse por la cosecha de patatas en una de las ermitas de Montserrat, le habían dicho que las habían importado de Inglaterra. Pero hay noticias de que a mediados del siglo XVIII las patatas eran frecuentes en la Cerdanya francesa. 
para gente pobre, de suerte que ha desterrado mucha hambre en el Valle de Aran este fruto» (Sanllehí, 2014).

El Valle de Aran no era la única comarca catalana donde las patatas eran cultivadas y consumidas. En 1787, en las páginas que se han conservado de la única memoria conocida sobre el producto, Mariano de Oliveras hablaba de un cultivo y un consumo bastante generalizado en el norte de Cataluña, especialmente en la Cerdanya, la Seu d'Urgell, Berga, etc. Aunque una parte del producto servía para alimentar a los cerdos, «la gente pobre hace con ellas su potage y los ricos hacen de ellas platos sabrosos y deliciosos» (Lluch, 1973). El mismo autor insiste en su importante papel en la mesa de los pobres: «las patatas se transforman en mil guisados bajo la mano de un hábil cocinero y en muchas partes es casi el único alimento de la gente pobre que las comen en potage, al rescoldo, cocidas en agua y después [con] un poco de sal, aceite y vinagre». Por su parte, el viajero Antoni Ponz destaca su cultivo en la parte más montañosa del obispado de Solsona: «se hace gran cosecha de unas raices que llaman tufas, las quales se multiplican, y propagan mucho: son de color acanelado, parecidas a las batatas silvestres. De ellas hace pan la gente pobre, y también las comen cocidas, sirviéndoles asimismo para engordar los cerdos» (Ponz, 1788, p. 139). En el valle de Ribas, el citado Francisco de Zamora criticaba en 1787 que en las iglesias hubiese «criadillas, judías y otros granos», por considerarlo «impropio, aunque sea con el pretexto de diezmos partibles y no tener otros depósitos» (Zamora, 1973, p. 195).

En las respuestas al cuestionario de Francisco de Zamora, que incluyen algunas áreas de alrededor de Barcelona y Tarragona, sólo hay referencias al tubérculo en las ofrecidas por los corresponsales del Valle de Arán, que ya hemos comentado, y en el Berguedà (Pérez Samper, 2008). El informante de esta última comarca explicaba en 1789 que en su parte más montañosa «también se cogen criadillas con bastante abundancia. Este fruto se ha introducido de pocos años a esta parte, sirve de sustento para la pobre gente, y los comen cocidos y mesclados con arina, hacen también pan de ellos, sirven también para engordar los serdos y toda especie de ganados, para los quales se aprovechan también las ojas» (Serra y Ferrer, 1985).

A pesar del comentario del mencionado Mariano de Oliveras sobre los «platos sabrosos y deliciosos» de patatas disfrutados por los ricos, lo cierto es que no hay referencias a ellas en los recetarios de cocina publicados antes de 1835 (Vila, 2010). Son bastante significativas al respecto las dos noticias aisladas aportadas por un hombre rico, el barón de Maldà, en su Calaix de Sastre durante el largo período que va de 1769 al 1819. El 19 de junio de 1795 recoge el comentario de unos fugitivos de

Y aún en este caso es posible que las recetas conciernan a las patatas de Málaga, es decir, a las batatas. 
Francia sobre el país que dejaban atrás, que aseguraban que «falta tot lo necessari per viure, que fa aquell poble privat generalment de menjar pa, reduït a menjar herbes, naps i patates» (Amat i de Cortada, 1987, vol. 5, pp. 245-246). Durante la guerra del francés, la mayor parte de la cual el barón la pasó en Berga, donde hemos visto era habitual el consumo de patatas, éste rechazó un plato que se le ofreció de ellas en la posada que visitó en 1809, ya que las consideraba un alimento propio de pobres (Amat i de Cortada, 1987, vol. 8, p. 194).

\section{b) Evidencias de la importancia de las patatas a mediados del siglo XIX}

La mejor evidencia de la consolidación de la producción de patatas en Cataluña nos la proporciona el Diccionario Geográfico Estadístico de Pascual Madoz, publicado en la década de 1840, donde se señala al tubérculo como producto importante en un buen número de municipios (Madoz, 1840-45; Vicens Vives, 1980; Fàbrega, 2017) ${ }^{9}$. Además, a partir de 1845 empiezan a proliferar las noticias sobre el mismo en diversos medios. Aquel año, por ejemplo, esas noticias vienen provocadas por la epidemia de Irlanda, como lo demuestran los nueve informes localizados en el archivo de la Academia de Medicina de Barcelona (Corbella, Gallegos, 2011). En ellos, los académicos muestran su preocupación ante la epidemia, porque «las patatas son el principal alimento de la clase proletaria». En años sucesivos, el Diario de Barcelona también se hará eco, por primera vez desde 1792, de los problemas causados por su carestía en muchas regiones de Europa central.

Si en algo coincidían las noticias internacionales con las domésticas era en señalar, y en confirmar, la importancia que había adquirido el consumo de patatas entre los pobres. Así, en 1847, el ayuntamiento de Girona informaba de que la crisis que se estaba viviendo en la ciudad había sido importante, no tanto debido a la carestía del trigo, sino del tubérculo, que era «el alimento del pobre», mientras que las estadísticas aportadas por Martínez Quintanilla a mediados siglo XIX para la provincia de Girona, hablan de la existencia de una producción per cápita elevada en todas sus comarcas (Congost, 1989). En la misma línea, en 1849 el hacendado y agrónomo Narcís Fages de Romà les dedicó un aforismo corto pero significativo: «Ab trumfas la Providència / Te deslliura d'abstinencia» (Fages de Romà, 1849). El escrito de Fages de Romà se inscribe en una etapa especialmente productiva de las élites ampurdanesas. En 1851-1853, en la revista La Granja leemos: «la patata ha librado a muchas familias y pueblos de los horrores

En el map. 1 aparece cartografiado el cultivo de la patata según los datos procedentes de Madoz. Aunque su cultivo se halla bastante extendido, estos datos señalan aún a las áreas de montaña como las máximas productoras. En cambio, los datos proporcionados por Martínez Quintanilla (1865), relativos a las cosechas de la década de los cincuenta, señalan que, en todos los partidos judiciales de la provincia de Girona, la cosecha anual superaba ya las 4,5 arrobas de patatas anuales por cápita. 
del hambre en épocas calamitosas que hemos atravesado y es en todo tiempo un gran recurso para el alimento del hombre y del ganado» (Heras de Puig, 1853).

No resulta sorprendente, pues, que en esos años el tubérculo hubiese pasado a formar parte ya de la dieta cotidiana de los hospicianos de Girona, tal y como lo revela el menú que aparece detallado en su nuevo reglamento de 1852 (Congost, 2018). Según el urbanista Ildefons Cerdà, las patatas también forman parte de la dieta cotidiana en Barcelona. En su estadística sobre la clase obrera de la ciudad en 1856, estima su consumo diario por las familias obreras barcelonesas en unos 1.400 gramos (Cerdà, 1867). Pero también, tenemos evidencias de ese consumo entre los ricos. El dietario de de un propietario de Girona en 1864, revela que en su caso el consumo diario familiar rondaba los 800 gramos $^{10}$, mientras que en un dietario de 1866 perteneciente a una familia acomodada de Palafrugell, comprobamos que el tubérculo formaba parte de la dieta de los enfermos. Y cuando Ramon Ordeig nos describe a mediados del siglo XIX lo que comían los estudiantes de Vic en el Colegio de San José, resulta que las patatas eran habituales en sus desayunos y cenas (Vila, 2010).

Por todo ello, resulta interesante señalar las diferencias establecidas en 1847 por el médico higienista Monlau entre el rol desempeñado por la patata en la alimentación de los ricos y la de los pobres (Monlau, 1847). Buen conecedor del debate abierto en Europa sobre los posibles efectos nocivos de un abuso en su consumo, reflexiona sobre las evidencias que éste tenía entre los ricos de este modo: «el uso de las especias, del azúcar, del café, del té, del vino, la mayor proporción de carne y las salsas más variadas, han contrabalanceado en las clases pudientes los efectos de la patata: para ellas, este tubérculo ha aumentado la variedad del régimen sin disminuir su potencia restauradora». Pero el dictámen de Monlau sobre el impacto de la patata en la alimentación de los pobres no ofrece ninguna duda. Después de responder negativamente a la pregunta: «¿serian éstos [se refiere a los pobres] más felices, estarían más lozanos, si no se hubiese introducido la patata?», concluía, «la casi desaparición de las carestías, o la atenuación de sus estragos, desde que se conocen [...], es el único hecho bien demostrado por la estadística; y este solo hecho absuelve de todo cargo al tubérculo en cuestión» (Monlau, 1847, p. 451).

\section{El peso de las ideas elitistas}

Como ejemplo del peso historiográfico de las tesis elitistas e institucionalistas en Cataluña podemos recurrir a las palabras que Jaume Vicens Vices y Montserrat Llorens dedicaron a la expansión del cultivo de la patata en Industrials i Politics: «la expan-

10 Se trata del dietario de la familia Pérez Claras. Debo a Pep Vila esta información. 
sión del maiz y de la patata muestra el éxito de las campañas de renovación agrícola y la dedicación de espíritus selectos a las cosas del campo» (Vicens i Vives, Llorens, 1980, pp. 27-29). La misma idea también se halla explicitada en el último estado de la cuestión publicado sobre el tema por Albert Fàbrega, «si a molts països europeus van ser les autoritats les que van empènyer -i en algun cas, com a Rússia, obligar- als pagesos a conrear patates, a Catalunya va ser sobretot una tasca dels sectors il·lustrats, que van tractar de convèncer a la pagesia de la utilitat de plantar patates i a la població de la bondat de consumir-les» (Fàbrega, 2017, p. 23).

Las dos afirmaciones, escritas con sesenta años de diferencia, prueban que en Cataluña, como en muchas áreas regionales europeas, está muy arraigada la idea de que el nuevo producto alimenticio necesita, para implantarse, de una institución o de unas élites que lo propaguen entre el conjunto de la población (Earle, 2018). El primer comentario, el de Vicens Vives, se acompañaba de un mapa donde se señalaban los lugares en que, según el Diccionario Geográfico Estadístico de Madoz, se cultivaban patatas. Albert Fàbrega, por su parte, reelabora y reproduce el mismo mapa y cartografía a su vez el cultivo del tubérculo según lo dicho en los trabajos de Frigola, en 1824, y de Golobardes, en 1831, lo que le permite ver con cierto detalle la progresiva evolución de su cultivo durante la primera mitad del siglo XIX, el cual había dejado de ser exclusivo ya de las áreas de montaña.

Como se ha dicho, las tesis elitistas no son incompatibles con la idea, bastante extendida, que presenta el consumo de patatas como algo que se hace eco de un cierto deterioro del nivel de vida de las clases populares, que se verían obligadas a alimentarse de ellas en tiempos de carestía a causa del elevado precio del pan. Al poner el énfasis en los precios, este enfoque lo pone también en la elección de la patata como alimento, no en su cultivo. Conforme al mismo, en la ciudad, si los precios de los cereales subían por encima de sus posibilidades, los pobres no tenían más remedio que comprar patatas. En consecuencia, los trabajadores urbanos, a menos que dispusiesen de un huerto, carecerían de capacidad de iniciativa en materia alimentaria. Cataluña, que había conocido un temprano proceso industrializador, podría haber vivido esta situación con una cierta intensidad.

Ahora bien, trasladada al campo, la misma idea explicaría la reticencia a cultivar patatas de un modo distinto al habitual, que hace ya años anticipó Michel Morineau (1970). En primer lugar, cabría suponer que los campesinos habrían tardado en alimentarse de ellas, no por ser ignorantes, sino por tener buen gusto, es decir, por no querer comer algo que percibían como negativo. Al mismo tiempo, en el caso de los campesinos independientes, la idea abre la puerta a que la elección de producir patatas pueda reflejar una capacidad de iniciativa propia, lo que estaría en consonancia con lo afirmado en algunas aportaciones recientes (Broad, 2013). Este planteamiento tiene 
sentido si consideramos que en sus orígenes las patatas sirvieron sobre todo como planta forrajera y que las élites, ya desde sus primeros escritos sobre las patatas, se interesaron sobre todo por la posibilidad de obtener pan a partir de ellas. De hecho, los primeros escritos de Antoine Parmentier trataban sobre esta posibilidad, que también es el tema que ocupa a la primera noticia escrita directa que tenemos en Cataluña sobre el tubérculo, en 1772 ${ }^{11}$ (Pérez Samper, 2008; Congost, 1990, p. 174).

Tanto el énfasis en la elaboración del pan como el uso industrial de productos derivados de la patata son pistas interesantes a seguir, pero es evidente que para avanzar un poco más en la línea discursiva que estamos defendiendo, nuestra principal tarea tiene que ser la localización y el análisis de los escritos que han permitido sustentar la idea de que fueron las élites las que convencieron a los campesinos de la bondad del cultivo del tubérculo. En este sentido, me referiré a continuación a los escritos de los ilustrados de finales del siglo XVIII, a un artículo de Antoine Parmentier publicado en el Diario de Barcelona en 1809, y a la serie de textos del mencionado Joan Francisco Bahí, publicados entre 1815 y 1821 . Todos estos autores han sido considerados «apóstoles de la patata».

\section{a) Sobre los ilustrados Manuel Barba, Mariano Oliveras} y el sacerdote Francesc Mirambell

Para finales del siglo XVIII e inicios del XIX disponemos en Cataluña de algunos testimonios que, como han puesto de manifiesto muchas investigaciones, parecen encajar perfectamente en las tesis elitistas. Me refiero a los ilustrados Manuel Barba y Mariano Oliveras, que eran primos hermanos, y al sacerdote Francesc Mirambell. Según Ernest Lluch, el vilafranquino Manuel Barba era conocido en los ambientes cultos como el «doctor patata», por su afición a hablar sobre el tubérculo (Lluch, 1973, p. 102; Bernat, 2008, p. 142; Iglésies, 1964, p. 15). Por su parte, Mariano de Oliveras fue autor del único trabajo que se conoce sobre el tema, titulado Ventajas y utilidades del cultivo y uso de las patatas, del que, desafortunadamente, solo se conservan algunas páginas. Al respecto, Pierre Vilar analizó en su día una correspondencia muy interesante mantenida entre los dos primos. Por ella sabemos que el 3 de febrero de 1787, el ilustrado Oliveras notificaba de esta manera a Barba el proyecto en el que estaba trabajando:

«Descenderé al particular de las patatas, dando una relación del origen y estado de su cultivo en Cataluña y de sus varios usos. Te aseguro que son preciosas las noticias que tengo recogidas sobre este particular y que voy recogiendo por medio de los

Cuando Arthur Young, en su primer viaje a Francia, establece contacto con Antoine Parmentier, elogia ante todo sus grandes conocimientos en el pan (Young, 1909). 
corresponsales. Absolutamente no falta sino enseñar a los labradores como hacer pan con ellas. Lo haré y lo presentaré a la Academia junto con una breve instrucción en catalán y el ofrecimiento de imprimirla a mis costes y de enviar cierto número de ejemplares a cada corresponsal y con una porción de pan si es menester. Digas sobre eso tu dictamen y con entera libertad; tengo ya grana de alfalfa, pero no las patatas que no han podido venir por el tiempo» (Vilar, 1975).

Vemos, pues, que Mariano de Oliveras no consideraba necesario extender la buena nueva del cultivo de la patata entre la payesía, sino sobre todo enseñarles a hacer pan. Aquel mismo año, Manuel Barba respondió a las 182 preguntas del amplio cuestionario de Francisco de Zamora relativas al partido y al Corregimiento de Villafranca del Penedés. En las referidas a los productos que se cultivaban en el territorio — pregunta 54 - y cual era la alimentación habitual — pregunta 161—, Barba no hacía ninguna referencia al tubérculo (Barba, 1991). Esto hace más interesantes las noticias de las actividades de la Junta de Caridad de Vilafranca, en cuya fundación había intervenido el mencionado Barba en 1800.

En un artículo del Diario de Barcelona titulado «Ensayos de sopas económicas» y publicado en 1803, se da cuenta de algunas de las medidas tomadas por aquella Junta para prevenir «la grande miseria que amenazaba el invierno de 1800». Sabemos así que la Junta había hecho plantar algunos millares de coles y sembrar nabos, pero que la nevada de ese año había sido tan extraordinaria, que «el pobre jornalero gemía en silencio por falta de trabajo». En este relato hay un fragmento que parece haber sido escrito para reforzar la tesis convencional del papel jugado por las élites en la propagación de las patatas en momentos de especial dificultad. En él, se dice, «a los jornaleros que no tenían jornal, se les dió la sopa y dos reales los días que cabaron los campos para sembrar patatas: se distribuyó una porción de estas entre los pegujaleros para sembrar; y un Individuo de la Junta ofreció premios a los tres que cogiesen mayor cantidad». Es decir, el salario con el que se pagó a esos jornaleros no fue especialmente bajo, y algunos de ellos, además, recibieron patatas, que plantaron ellos mismos en sus pequeñas parcelas, es decir, en sus pegujales ${ }^{12}$. A continuación, el portavoz de la Junta valora el posible impacto de sus acciones, diciendo «con estos estímulos se aumenta cada año la cosecha de patatas, a la cual se prestan los campos pingües de este termino, a pesar de la escasez de lluvia en el verano. La Junta distribuye las suyas entre los pobres, que se acostumbran a este nuevo alimento, y en particular los niños, que las piden con importunidad: se hacen tambien pan y tortas,

12 Según Belén Moreno (2005), que sigue en esto a Emilio Giralt, en las décadas de 1780-1790 en Vilafranca se solían pagar tres sueldos más la manutención. En este caso, se trataría de cuatro sueldos y la sopa; además de las patatas para plantar, en los casos en que disponían de pequeñas parcelas. 
y se emplean para las sopas». O sea, que el portavoz de la Junta de Caridad de Villafranca, al mismo tiempo que nos informa sobre el cumplimiento de una actividad habitual de este tipo de organizaciones, consistente en la distribución de alimentos entre los pobres, nos hace saber que se iban «acostumbrando» al tubérculo y que las nuevas generaciones, representadas por los niños hambrientos, parecían no hacer ascos al nuevo producto. Pero el párrafo nos dice también algo más sobre lo que queremos llamar la atención. Señala como hecho principal, y tal vez como principal novedad, que aquel año se plantaron patatas en «los campos pingües» del término de Vilafranca. Es decir, supone que la escasez de cereales había aconsejado, aquel año extraordinario, plantar patatas en las tierras de los mansos donde se acostumbraban a sembrar cereales. Muchos de estos mansos estaban siendo explotados por masoveros y, en consecuencia, los propietarios podían obligarles a cultivar patatas. Los pegujaleros, en cambio, probablemente podían actuar por cuenta propia. A lo largo de este trabajo insistiremos en esta contraposición entre mansos y pequeñas parcelas, en lo que constituirá también el principal contraste que se aprecia entre los escritos de Parmentier y Bahí.

El cura Francesc Mirambell es otro caso paradigmático, pues encaja a la perfección en las tesis elitistas. En su caso, la principal referencia que tenemos sobre su apostolado es la que nos proporciona él mismo, en una exposición de méritos dirá:

«En el año 1792, compadecido de la miseria que pasaban sus feligreses en la villa de San Martín de Sasgayoles, se aplicó cuidadosa e infatigablemente en fomentar allí la agricultura y para que el socorro fuera pronto comenzó con el cultivo de las patatas que eran tan desconocidas allí como en la comarca. Correspondieron a sus deseos unos resultados tan felices como que aquella feligresía tuvo pronto socorro; y desde aquella época aquel fruto precioso forma un artículo considerable en la cosecha de aquella vila, de su comarca y de varios términos de sus contornos, por donde su cultivo se va extendiendo más y más» (Bernat, 2005).

En suma, y dejando a un lado el marcado carácter autopropagandístico de todas las referencias que acabamos de presentar, unas y otras alimentan ciertamente la tesis de la existencia de unos espíritus selectos interesados en la propagación de la patata. En todos los casos se trataba de gente culta. Es más, sabemos que en la biblioteca de Francesc Mirambell no faltaba el Diccionario de Agricultura del abate François Rozier, donde Parmentier había publicado un extenso capítulo sobre el tubérculo, cuya traducción se reproduciría luego, en 1809, en el Diario de Barcelona y en el Semanario de Agricultura, publicación esta última dirigida a los párrocos. Pero aún así, cabría preguntarse, ¿fueron los Barba y los Mirambell realmente los verdaderos artífices del proceso de difusión de la patata en el campo catalán? En el Diccionario Geográfico Estadístico de Madoz, que como hemos visto ha sido utilizado reiteradamente para 
señalar la importancia de su producción en la década de 1840, ni Sant Martín, ni el partido judicial de Igualada, al que pertenecía este municipio, ni la ciudad, el partido o el corregimiento de Villafranca del Penedés, área de influencia de las actividades de Manuel Barba, son reseñados como productores de patatas (Madoz, 1845-1850) ${ }^{13}$. Aunque, tal vez, sea más relevante en este sentido el artículo que el mismo Francesc Mirambell publicó en abril de 1816 en las Memorias de Agricultura y Artes, la revista de Juan Francisco Bahí, que aparece repleto de ejemplos, de iniciativas, que aseguraba haber visto con sus propios ojos llevar a cabo a los labradores, algunos de ellos «sencillos» y con poca tierra, que «han mejorado visiblemente las producciones y haciendas con solo comunicarse sus privadas y sencillas observaciones» (Mirambell, 1816).

\section{b) La sombra de Parmentier}

Si algún nombre representa, a nivel internacional, la fuerza de la tesis elitista, este es sin duda el del farmacéutico francés Antoine Parmentier. Si hemos considerado oportuno referirnos a él aquí, es porque en los meses de febrero y marzo de 1809 se reprodujo en el Diario de Barcelona un extenso y conocido trabajo suyo en castellano (Parmentier, 1789). En el artículo, especialmente en aquellos fragmentos que podemos considerar autobiográficos, y por lo tanto, en cierta manera, susceptibles de ser condiderados autopropagandísticos, se reproducen repetidamente las bases de las tesis elitistas. En particular, cuando dice:

«La influencia de las preocupaciones y de la rutina en la opinión de los habitantes del campo no debe ser motivo para abandonar el proyecto de instruirlos cuando se toma interés en su felicidad. El ejemplo, que sin duda es el precepto más seguro de todos, ha sido ya empleado con fruto por muchos ciudadanos recomendables; gracias a su instrucción y a los medios de que se han valido para animar al labrador».

En el momento en que ha escrito este trabajo, Parmentier parece haber renunciado ya a la idea de la elaboración del pan de patatas que había protagonizado alguno de sus primeros trabajos, y explicaba ahora de qué modo lo había hecho saber a los «pobres cultivadores»:

«He aquí el lenguaje con que incesantemente he hablado a los pobres cultivadores, cuya suerte me compadece verdaderamente: Gastad siempre las patatas como las produce la tierra, cuando hay abundancia de granos; en los años medianos mezcladlas con su harina, y si no tuvieses absolutamente otros recursos para

$13 \quad$ Sí lo es Campdevànol, el primer pueblo en el que ejerció como sacerdote Francesc Mirambell, que formaba parte del partido de Ribes de Freser y también el partido de Vic, donde se había criado de niño. 
subsistir más que estas raíces, destinad una parte de ellas para pan, a fin de que tengáis en todos tiempos un alimento bajo la forma acostumbrada. No temáis que su cultivo perjudique al del trigo; además que ni originarán monopolios ni hambre».

Parmentier no desaprovecha la ocasión para explicar los consejos que «estoy dando quince años hace con el zelo que debe inspirar el vivo deseo de ser útil». Y en el apartado «De los diferentes métodos de cultivarlas», vuelve a hacer referencia al apostolado que ha llevado a cabo en los años anteriores. Pero lo que nos interesa de este apartado, es el énfasis que pone en la necesidad de que se dediquen al cultivo del tubérculo grandes extensiones del terreno. En cada uno de los cinco métodos que describe, el arado, del que solo disponen los labradores con explotaciones de ciertas dimensiones, desempeñaría un papel importante. De hecho, antes de pasar a describirlos, Parmentier ya ha advertido «que este cultivo no será realmente útil a la mayor parte de nuestras provincias, mientras no se ejecute en grande y con animales, como se cultivan las viñas en Gascuña». Para más adelante concluir, «en fin, diremos que el cultivo a brazo es dos veces más dispendioso que el de animales, y que este debe preferirse cuando se quiere cultivar en grande esta planta a fin de darle sin mucho costo las labores que exige, y sacar de ella una cosecha abundante».

Hemos querido destacar la defensa de Parmentier del cultivo de las patatas en extensiones de terreno de cierta magnitud, las cuales corresponderían en el paisaje catalán a los masos, para contrastarla, primero, con lo dicho en los escritos publicados después de la Guerra de la Independencia por quien ha sido considerado una especie de Parmentier en Cataluña, el médico Joan Francico Bahí y, después, para compararlos con la realidad catalana.

\section{c) Siguiendo la pista de Joan Francisco Bahí (1815-1821)}

El conjunto de los trabajos a los que nos referimos en este apartado han permitido presentar a Bahí como una especie de apóstol de la patata (Maspons, 1907-1916; Bernat, 2008, pp. 84-88). Sin embargo, desde nuestro punto de vista, lo que esos trabajos revelan son dos cosas. La primera, que probablemente sea cierto que la Guerra Gran (1793-1795) y la Guerra de la Independencia (1808-1814) significaron el definitivo impulso a la difusión de su cultivo, aunque, lamentablemente, la escasez en las fuentes de noticias nos impida afirmarlo con rotundidad ${ }^{14}$. La segunda, que lo que

Además de las evidencias que aporta el mismo Bahí, disponemos de algunos pocos datos aislados. Serra de Manresa (1996, p. 283) ha verificado que el libro de los gastos de la comunidad de capuchinos de Martorell registra por primera vez la compra de patatas en abril de 1812. Este año, la Gazette de Girona ya publicaba el precio de las patatas en el mercado de Figueres. En el Diario de Barcelona del 16 de octubre de 1815, un escrito firmado por D.R.N. hace referencia a las penurias vividas ese año de esta forma: «asolado en esta mi patria comiendo la pura patata me tocó sufrir la 
buscaba Bahí era, sobre todo, convencer a los propietarios del conjunto de España de la necesidad de substituir el consumo del pan por el de patatas, tal y como opinaba había sucedido en Inglaterra, Holanda y buena parte de Cataluña, y precisamente por ello, porque en Cataluña ya se había conseguido, quería exportar lo sucedido aquí al resto de la Peninsula.

Respecto a la primera consideración, en el «Prospecto» del primer número de las citadas Memorias, fechado en julio de 1815, leemos:

« $i$ Quantas semillas pueden connaturalizarse y germinar en nuestro país, de que hasta ahora apenas tenemos idea! ¡Quanto podria aumentarse la agricultura, alternando su cultivo con el de los granos sin desubstanciar, antes benediciando mucho las tierras! ¡Y que abundancia de alimentos saludables podríamos prometernos de su introducción! Díganlo las patatas, que a fines del siglo último apenas eran conocidas en esta provincia, y en los calamitosos años de la guerra han salvado tantas vidas de la hambre y de la miseria».

Además, en el número del diciembre de 1815, Bahí señala la bondad de las tierras arenosas para el cultivo de las patatas con una nota a pie de página que hacía referencia a la importancia que había adquirido su cultivo en la zona del Montseny durante los años de la guerra contra el francés. En febrero de 1816, Bahí firmaba su primer artículo dedicado enteramente al tubérculo, colmándolo de elogios al hablar sobre las ventajas de su cultivo para combatir el hambre.

Respeto al modelo de consumo propugnado, basado en lo ocurrido en Cataluña, Bahí valoraba muy especialmente el hecho de que la producción de patatas permitiese al pequeño campesinado vivir con poca tierra y por ello asociaba su difusión a una práctica jurídica que él y su familia conocían bien, la enfiteusis ${ }^{15}$. Pero, vayamos por partes.

cárcel opresión y ojeriza de la vil polilla...». En general, el seguimiento de las noticias publicadas en este diario, permite observar una familiarización progresiva con el tubérculo. Así, el 15 de noviembre de 1819 se informa de la llegada a Bélgica de «una especie de patata importada de Inglaterra, desconocida en el continente». El 5 de marzo de 1820 es el corresponsal de Marsella quien informa de la llegada a esta ciudad procedente de Londres de «una patata de especie desconocida en el continente, y tan productiva, que habiendo sembrado dicho sugeto el fruto que dio por primera vez en aquel suelo, ha cogido 2160 libras de patatas; cuya especie sino degenera será de la mayor utilidad a nuestra agricultura». Las noticias sobre las múltiples posibilidades de las patatas también empiezan a proliferar. Así, el 16 de abril de 1819 el periódico barcelonés se hace eco de una conferencia pronunciada en Barcelona por Francisco Sanpons sobre la fabricación de arroz y aguardiente de patatas, y en el Diario del 28 de febrero de 1820, se explican las experiencias hechas en el departamento de Gers, en Francia, que confirman «la propiedad que ya se había reconocido en la patata de servir de jabon para lavar toda clase de ropa, tanto fina como basta».

15 Bahí provenía de la familia Bahí de la Pera, una familias de hacendados que había destacado en la concesión de establecimientos enfitéuticos, Congost (1990). 
Al médico Bahí, que había ejercido su profesión en Burgos, le interesaba mostrarse como un buen conocedor de la realidad española, para de este modo hacer más persuasivo su discurso. En diversas ocasiones, establece en su obra fuertes contrastes entre Cataluña y España. La miseria que, en su opinión, dominaba en el conjunto de la Península, se limitaba en Cataluña a unas pocas comarcas, entre las que destacaba la de Urgell, donde, decía, la gente se veía obligada a emigrar, «asi por desgracia tambien nos lo demuestran ahora los infelices habitantes del seco Urgel reducidos igualmente a la sola cosecha de panes, sin haberse dado a los prados artificiales ni al variado cultivo de patatas». Esta realidad contrastaba con lo sucedido en el resto de Cataluña, que merecía estos elogios:

«La alternativa y variedad de cosechas, y suma laboriosidad de los demás labradores catalanes, y la exportación de nuestros frutos, evita este escollo, en nuestro Principado; por lo que nuestras aldeas presentan una perspectiva muy distinta de los campos aragoneses, manchegos, andaluses, extremeños y castellanos: aquí hay comodidades domésticas, y hasta un lujo en las familias robustas de nuestros jornaleros».

En mayo de 1818 encontramos otra referencia favorable a Cataluña en su conjunto, en la cual vuelve a quedar claro que la pequeña propiedad puede ser la solución:

«En Cataluña como son mas los propietarios, y apenas hay en los lugares y aldeas del Principado un artesano, menestral o jornalero que no tenga su pieza de tierra, viña o huerto propio o en arriendo para cultivarle por sí o a su cuenta, hay una razón más o un interés comun, para que sea respetado el fruto del campo ageno».

Una de las fórmulas que había impulsado la pequeña propiedad en Cataluña había consistido en el contrato enfitéutico. Bahí se refiere varias veces del mismo como solución para toda España. Así, en mayo de 1817, recomienda a los propietarios que repartan las tierras por medio de contratos enfitéuticos y no duda en relacionar esta práctica con el cultivo de las patatas, ya que en las nuevas parcelas se destinará «la mitad o las terceras partes de esas tierras de labor o baldíos para prados artificiales, y la otra mitad o tercera parte para los cereales y para el riquísimo e importantísimo cultivo de patatas», y concluye, «esta suscinta fórmula, llevada a efecto por nuestros labradores, transformará en pocos años la nación española, teniendo la gran mira los propietarios de repartir sus dilatadas haciendas en heredades menores, dadas al censo o renta anual en moneda o en frutos».

En la misma línea, Bahí también vio la oportunidad de extender el cultivo de la patata al conjunto de España en las medidas liberales que proponían la asignación de pequeñas parcelas de terrenos baldíos a «soldados y marineros beneméritos de la 
Patria». Lo vemos en la memoria publicada en septiembre de 1820, donde considera la necesidad de dividir y dar esos terrenos «en propiedad, a censo o en enfiteusis, a los nuevos y numerosos colonos», los cuales sabrían «escoger una parte del terreno de mejor calidad para el cultivo variado de las cereales, legumbres, patatas, cáñamo y lino, etc., con cuyos productos en pocos años se constituye cada familia muy acomodada ó con sobrantes, y en cuyo sentido se puede ya llamar rica».

Bahí hablaba desde la experiencia. En su Jardín Botánico había partido de una extensión muy pequeña de tierra para demostrar que su propuesta era viable:

«Con la corta estension de sesenta varas cuadradas de terreno en que cultiven las patatas en zanja, plantando en la cima de los caballones habas, y cebollas en los lados, tiene una familia rústica assegurada la abundancia de estos tres comestibles para su alimento anual; y á poco que favorezca la estación, sobrarán de estos frutos, particularmente las patatas para el ganado, en especial para el de cerda, cuya cria debe entrar siempre en la cuenta del labrador, particularmente de la madre de familia que nunca debe descuidarlo, como á uno de los primeros renglones de su despensa doméstica».

Sus observaciones no solo contrastan con la insistencia de Parmentier en la necesidad de que el cultivo de patatas se llevase a cabo en las grandes heredades, sino que nos interpelan directamente: durante muchos años, la historiografía agraria dominante en España había tendido a descalificar cualquier medida de reforma agraria - como la que comenta Bahí - consistente en un repartimiento de pequeñas parcelas de tierra ${ }^{16}$.

\section{Una interpretación no elitista es posible}

No conocemos a ningún noble catalan que se deleitara usando el tubérculo como alimento, a semejanza de como supuestamente había hecho el rey de Francia a instancias de Parmentier, o incluso el mismo rey de Prusia. Los experimentos y escritos de los ilustrados catalanes del siglo XVIII no permiten atribuirles la difusión de la patata como la opinión pública francesa ha hecho con Antoine Parmentier. Alrededor del farmacéutico se forjó una leyenda que encajaba perfectamente con la imagen que él había transmitido cuidadosamente de sí mismo en sus escritos, sustentada siempre sobre la necesidad de instruir a unos campesinos ignorantes ${ }^{17}$. A grandes rasgos, la

\footnotetext{
16 Por ejemplo, en relación al proceso desamortizador, las propuestas de Flórez Estrada. Sobre la necesidad de un replanteamiento historiográfico de esta cuestión a partir de las investigaciones realizadas en las últimas décadas, véase Congost (2018).

$17 \quad$ El papel legendario de Parmentier en el proceso de difusión de las patatas ya fue impugnado por algunos de sus contemporáneos, como muestra el artículo de Dubuc (1953) sobre Normandía.
} 
leyenda dice así: Parmentier consiguió del rey cierto terreno cercano a París, donde plantó patatas. Durante el día había unos guardias que vigilaban la plantación, pero por la noche la plantación no estaba vigilada. En realidad, todo había sido planeado por Parmentier con el objetivo de atraer a los campesinos al cultivo de la patata.

En este punto no deja de ser interesante constatar que la única leyenda que conocemos sobre los orígenes del tubérculo en Cataluña, recogida por Josep Iglésies, no hace intervenir a ningún «espíritu selecto» ni a ningún noble, ni a ningún rey, ni da cuenta de ninguna estratagema, en el inicio de su cultivo. Al contrario, el relato situa los inicios de ese cultivo en el hecho azaroso de que un payés lanzase al estercolero una de las patatas que el ejército empleaba para alimentar a los soldados:

«Hem sentit contar al veïnat de Cabrera (terme municipal de Mont-ral que, al primer terç del segle passat, un noi d'un mas del redol, mobilitzat per a servir l'exèrcit, en tornar a la casa pairal en un dels seus permisos, va portar unes patates per ensenyar als seus pares «les porqueries que els feien menjar a soldat». Després d'examinar aquelles arrels, el pare menyspreativament va llençar-les a un femer. La seva sorpresa va ser veure fructificar amb ufana aquell femer en venir la primavera. El muntanyenc que ens contava el fet gosava afirmar que tota la patata, que va servir per expandir el seu cultiu a les muntantes de Prades, procedeix d'aquell femer de Cabrera» (Iglésies, 1964, p. 15).

Esta referencia al ejército encaja con la coyuntura real del proceso de difusión del cultivo, y no deja de ser interesante la atribución, no sólo del descubrimiento, sino también de ese proceso de difusión a la observación de un payés acerca de lo que sucedía en un estercolero, sobre todo si contrastamos esta historia con la de Parmentier.

Aunque más allá de la mencionada leyenda, cabe preguntarse, ¿qué sabemos sobre el proceso real de difusión de la patata en el campo catalán? En él, sin duda, contrasta el elevado número de evidencias que tenemos sobre su consumo para los años centrales del siglo XIX con la escasez de noticias que hay en las décadas inmediatamente anteriores. Ante esto, lo único que podemos hacer es señalar algunos silencios significativos aparecidos en fuentes específicas, visto que, y a diferencia de lo sucedido en Galicia, donde el cobro del diezmo de patatas ha servido para certificar y cartografiar la difusión del nuevo cultivo, en Cataluña apenas hemos encontrado evidencias de este tipo ${ }^{18}$. Ahora bien, la apatía mostrada en este sentido por los diezmeros ante la posibilidad de hacerse con este producto podría tener mucho que ver con el carácter

18 Sobre Galicia, Fernández González (1994) y Sobrado (1996). En la diócesis de Girona solo hemos hallado una parroquia donde los diezmadores del lugar exigieran el diezmo de la patata. Se trata de una concordia firmada en 1804 entre los diezmadores y los habitantes de Peratallada, en la comarca del Baix Empordà. 
doméstico de su consumo, al menos en una primera etapa. Encajaría con esta hipótesis el hecho de que los contratos de arrendamiento de masos tampoco aportan información sobre su cultivo, así como algunos rasgos que persisten en el lenguaje cotidiano actual, que evidencian el triunfo de las formas lingüísticas populares y rurales sobre las institucionales y urbanas. Pero, veámoslo en detalle.

\section{a) El silencio en los contratos de masovería: el caso de la región de Girona}

Las referencias a la región de Girona no han sido escasas a lo largo de este trabajo. La primera de ellas, relativa a un intento de elaborar pan con patatas la hemos hallado en el ayuntamiento de esta capital en 1772. Por otra parte, en $1812 \mathrm{el}$ tubérculo se vendía ya en el mercado de Figueres. De hecho, la mercurial de Girona incluye el precio de la patata desde 1824 . Y hemos visto que su consumo se hallaba bien asentado en la región a mediados del siglo XIX, tanto en la mesa de los pobres como en la de los ricos. Al respecto, no hay que perder de vista que el mencionado Bahí procedía de una familia gerundense, mientras que Heras de Puig, un hacendado de la ciudad, certificaba la extensión de su cultivo en el conjunto de la provincia a mediados del siglo XIX:

«Cultivada después entre nosotros exclusivamente para el ganado de cerda, al cual se daba aún con cierta recelosa desconfianza, ha venido a ser en nuestros días y particularmente en esta provincia una de las producciones más importantes de la agricultura. En las cordilleras y los estribos de los Pirineos, en los partidos de Ribas, Olot, Figueres y Santa Coloma, se cosecha gran cantidad de este tubérculo y aunque en las llanuras no está tan generalizado su cultivo, es de notar sin embargo que no hay pueblo alguno donde la patata no haya adquirido ya carta de vecindad y aún cierta importancia» (Heras de Puig, 1853).

En esta región, en el último tercio del siglo XVIII, es decir, en los inicios de la historia que queremos explicar, la mayor parte de las tierras cultivadas las constituían los masos, aunque el grueso de los agricultores se limitaban a trabajar pequeñas parcelas. La riqueza de sus archivos notariales, en comparación con otras regiones catalanas, la convierten en un área especialmente privilegiada para llevar a cabo el estudio que proponemos. Y ello por dos razones: a) porque durante el período de expansión del cultivo de la patata, los propietarios de los masos formalizaban ante notario los correspondientes contratos de masovería, que incluían numerosos y detallados pactos; b) porque durante ese mismo período, las referencias utilizadas en la documentación notarial y, de hecho, en todo tipo de documentación de esta naturaleza, nos permiten distinguir sin problemas entre los cultivadores de los masos, llamados payeses, y los cultivadores de las parcelas, llamados trabajadores, los cuales, desde fines del siglo XVIII, serán conocidos como menestrales (Congost, 2014). 
Hemos examinado cientos de contratos de masovería pero en ninguno de ellos hemos encontrado referencias al cultivo de las patatas (Congost, 1990, pp. 133-182) ${ }^{19}$. Es significativo que las escasas noticias que tenemos sobre ese cultivo a manos de los masoveros sean indirectas. Así, en una correspondencia privada del Baix Empordà de la década de 1840, podemos leer que los cerdos eran alimentados con las «trumfes sobrants», y sabemos que el tubérculo desempeñaba entonces un papel importante en aquello que era conceptuado en los escritos de la época como «cultivo alterno». Por su parte, Ramon de Sabater, que ostentaba el título de marqués de Capmany, publicó en 1854 en un número de la Revista del I.A.C.S.I., un artículo sobre ese «cultivo alterno». Refiriéndose a la patata como uno de los productos que los payeses acostumbraban a sembrar durante la fase del barbecho del trigo, decía:

«Así como la mitad de la hacienda estaba sembrada de trigo o centeno, según la calidad de la tierra, la otra mitad se hallaba dividida en dos partes a poca diferencia iguales, de las cuales layan una para la siembra de las cucurbitáceas citadas, patatas, forrages de primavera, habas, etc. [de esta manera, proseguía...] el cultivador del sistema alterno atenua los daños del granizo con los tubérculos y raíces que tiene enterrados, alivia el hambre con la leche y quesos de los ganados».

El 9 de abril de ese mismo año, el Diario de Barcelona se hacía eco de una conferencia de Isidoro de Angulo sobre la elección de un buen sistema de cultivo para el tubérculo, el cual consistía en suprimir el barbecho y plantar patatas.

Estas evidencias nos permiten reinterpretar el silencio sobre el cultivo del producto en los contratos de arrendamiento, esto es, de masovería. En la región de Girona, a fines del siglo XVIII y principios del siglo XIX, después de una etapa en que se prohibieron los cultivos durante el barbecho, se generalizó la fórmula «tercio de granos y de todo género de frutos», pudiendo incluirse en ese tercio a las patatas. Aunque es interesante observar que la aparición de esta fórmula habría sido consecuencia de la incapacidad de los propietarios para preservar el barbecho blanco frente a la iniciativa de los masoveros, aspecto este que también cuestionaria la idea de que el tubérculo hubiese sido difundido por las élites (Congost, 1990; Congost, Planas, Saguer i Vicedo, 2010).

19 En el trabajo referenciado se analizaron los contratos de masovería sujetos a aparcería de más de 300 masos dispersos por la región de Girona durante el período 1768-1862. Esta región destaca, en el conjunto de Cataluña, por el elevado índice de escriturización notarial de este tipo de contratos, en los cuales se detallaban numerosas cláusulas y pactos referidos al cultivo de las tierras de las heredades. La ausencia de cualquier referencia a las patatas en los contratos examinados resulta, por esta misma razón, especialmente significativa. 


\section{b) Evidencias del empuje, y de los saberes, de los pequeños propietarios}

Los datos que reflejan un consumo generalizado de la patata en las familias humildes a mediados del siglo XIX, sugieren el importante papel que habían podido tener en su difusión los pequeños propietarios. Los integrantes de este grupo social eran a menudo analfabetos y raramente dejaban constancia escrita de las decisiones que habían tomado de forma autónoma, lo que explicaría la falta de noticias que tenemos sobre el particular. Aún así, algunas investigaciones recientes parecen evidenciar, a partir de los análisis de los capítulos matrimoniales y de los inventarios post mortem de la región de Girona, la existencia de mejoras en el nivel de vida de una parte substancial de los llamados trabajadores, cultivadores de pequeñas parcelas, a fines del siglo XVIII, antes de la Guerra Gran y de la Guerra de la Independencia (Congost, Ros, Saguer, 2016). Es decir, antes de que esta mejora pueda ser atribuida al propio proceso de expansión del cultivo de la patata que, de acuerdo con todos los indicios, tuvo lugar sobre todo durante los mencionados períodos bélicos. Pero los cambios experimentados en los niveles de vida de este grupo social son demasiado amplios como para seguir aceptando, sin más, el argumento de su ignorancia y su conservadurismo en los temas agrarios que las tesis elitistas han venido reforzando.

En Cataluña, los avances de la vid nos ofrecen un buen ejemplo de ese saber campesino que las élites propietarias intentaron frenar. Me refiero al sistema de los «colgats y capficats» que permitían renovar la vida de las viñas. Como es sabido, este método fue duramente combatido por los propietarios, ya que las mencionadas viñas se cultivaban en pequeñas parcelas que éstos habían concedido a los campesinos «a rabassa morta», y por eso les molestaba su iniciativa en este terreno.

Por otro lado, muchos trabajadores habían accedido a la tierra por medio de contratos de enfiteusis concedidos por las élites. La contrapartida, en este caso, habría podido ser la pérdida de usos y derechos comunales sobre las tierras, pero los productos de los huertos y de las pequeñas parcelas en manos de pequeños propietarios proporcionarían buena parte de los alimentos que antes, tal vez, habían suministrado esos bienes. También aquí pudo desempeñar un importante papel la plantación de la patata como substituto, no ya del pan, sino de otros productos alimenticios tradicionales. En este sentido, la consolidación durante el siglo XVIII en la mayoría de áreas catalanas del cobro del salario agrario en dinero, podría asimismo haber beneficiado al pequeño propietario. Es significativo al respecto que en sus escritos Joan Francisco Bahí hable del «lujo en las familias robustas de nuestros jornaleros» y que utilice la etiqueta de «menestral» como sinónimo, precisamente, de pequeño propietario. Un sinónimo que también es utilizado en un «aforismo» de Narcís Fages de Romà escrito en 1849, el cual pretende resumir el carácter emprendedor de este grupo social: «Lo cultiu del menestral / Observeu-lo que bé ho val / Si es donés a l'heretat / Altre fora el resultat» (Fages de Romà, 1849). 


\section{c) Las pistas del vocabulario: el atlas lingüístico de la «trumfa» y la patata}

Cuando Narcís Fages de Romà dedica uno de sus «aforismos» a las patatas, decide utilizar otro vocablo para designarlas: «Ab trumfas la Providència / Te deslliura d'abstinença». Seguiremos pues esta pista, y lo haremos por orden cronológico. Aunque en los trabajos manejados los expertos se referían a las patatas, en su viaje de 1787, Francisco de Zamora hablaba en cambio de «criadillas» y explicaba que los catalanes las llamaban trufas o truas. Sus corresponsales, y el autor del Discurso atribuído a Caresmar, confirman el uso de esta palabra que tiene también su correspondencia en la Cerdanya francesa desde mediados del siglo XVIII.

El trabajo de Parmentier traducido al castellano y publicado en 1809 en el Diario de Barcelona, si bien escrito en 1786, es decir, en los mismos años en que viajó y escribió por Cataluña el mencionado Francisco de Zamora, empieza mostrando una doble preocupación por el vocabulario. En primer lugar, por el hecho de que parecía muy corriente la confusión entre las patatas y las otras especies: «se ha confundido y se confunde todavía la patata con la pataca ó patata de caña y la batata». El traductor había traducido la frase que, en francés, decía: «on la confond encore tous les jours avec la patate \& le topinambours». Por suerte, en el mismo párrafo se aportaba la solución científica al problema, gracias al recurso al latín, la patata — pomme de terre en francés - era un solanum; la batata - patate en francés - eran un convolvulum; y la patata de caña - topinambour en francés - era un corona solis. Las quejas de Parmentier tenían sentido. En su país, la Encyclopedie había considerado pomme de terre, topinambour, batate, truffe blanche, truffe rouge, como sinónimos (Bruneau, 1932; Kawaguchi, 2017). El aviso de alerta era también pertinente en España. En las sucesivas ediciones del Diccionario de la Real Academia Española del siglo XVIII, desde la primera vez que aparece el vocablo «patata», en 1737, tan solo se indica: «lo mismo que batata». El nombre americano original, «papa», también aparece por primera vez en esta edición, con un comentario negativo que no desaparece hasta 1803, «es comida insípida». A partir de la edición de 1817, la voz «papa» remite a la voz «patata».

La «batata» merece una definición completa y autónoma desde la primera edición del Diccionario, en 1726, y sólo en la de 1786 se explica, «también les llaman patatas». Pero en todas las ediciones del siglo XVIII se especifica que se «crian muchas en Málaga». Es posible que la traducción al castellano del artículo de Parmentier sirviese para aclarar los conceptos y explique algunos de los cambios perceptibles en la edición de 1803 , donde la voz patata y el nombre americano original, «papa», merecen por primera vez un redactado propio, además de que el diccionario recoge las definiciones de «patatas gallegas» $\mathrm{y}$ «patatas manchegas», que es la forma adoptada por el traductor para diferenciar las «patatas blancas» de las «rojas, largas y redondas», según el 
original francés. En 1803 también aparece por primera vez la palabra «pataca», que es asimilada a la «patata de caña». En la edición de 1817 el nombre latín helianthus tuberosus no ofrece dudas de que se trata del tupinambour francés ${ }^{20}$.

La segunda preocupación de tipo linguïstico de Parmentier hace referencia a las múltiples palabras utilizadas para designar a las «patatas auténticas», entre las que destacan la truffe blanche y la truffe rouge, que el traductor Alvárez Guerra convierte ahora en «criadilla de tierra blanca» y «criadilla de tierra rosa». El Diccionario de la Real Academia Española no sirve demasiado para interpretar el lenguaje utilizado por los campesinos catalanes, pero aporta algunos datos significativos respeto a ambos vocablos. La expresión «criadillas de tierra» aparece por primera vez en la edición de 1780; en la de 1788, en la voz «Trufa», se explica que con esta palabra «llaman en Castilla la Vieja a las criadillas de tierra» ${ }^{21}$. Hasta la edición de 1884, no se señalará que esta acepción viene del francés truffe.

Frente a la confusión y a la complejidad reflejada en los Diccionarios de la Real Academia Española, el autor de los dos volúmenes del Diccionario catalán publicados en 1839 y 1840, Pere Labèrnia, parecía tener ya bastante claro que las patatas, las batatas y las trunfas eran una misma cosa. Así, en la voz «batata» se limita a señalar que significa patata y en la voz «trumfa» leemos: «patata del país». Como traducción castellana se ofrece: «batata, criadilla de tierra, trufa». Ni la consideración de la «papa» como un tubérculo ni la voz «pataca» aparecen en el diccionario (Labèrnia, 1839).

La definición de «trunfa» como «patata del país», es decir, como producto autóctono, invita a interpretar la persistencia de este vocablo hasta prácticamente nuestros días en gran parte de Cataluña como un indicio de que la difusión del tubérculo respondió a iniciativas llevadas a cabo por las clases populares. En 1914, el filólogo Alcover se hizo eco, en el Butlletí del Diccionari de la Llengua Catalana, de un estudio publicado en una revista alemana sobre la evolución y la difusión de los nombres relativos a las plantas nuevas del maíz y de la patata en Francia (Alcover, 1914; Spitzer, 1913). Su autor, había partido del Atlas Linguistique de France (Gilliéron y Edmont, 1902-1920), y consideraba que la palabra sabia pomme de terre había conseguido imponerse sobre la primitiva patate y otros nombres,

$20 \quad$ Las sucesivas ediciones de los Diccionarios de la Real Academia Española han sido consultadas en la página web de la Real Academia Española: www.rae.es.

21 De hecho la voz criadilla era también reciente, ya que había aparecido por primera vez en la edición de 1780 , como «raíz redonda sin tallo ni hojas que produce la tierra. Dícese comúnmente criadilla de tierra». En 1817 la explicación dada es un poco más larga, «especie de hongo sin raíz, globoso, sólido, negruzco y con puntitas por de fuera, blanquecino o pardo, rojizo y algo oloroso por adentro. Se cría debajo de la tierra y después de guisado es muy sabroso». Esta definición se va reproduciendo hasta la edición de 1853, a la cual se le añade lo siguiente: «llámase por otro nombre trufa, especialmente en algunos pueblos de Castilla». 
entre los cuales se hallaba la truffe $e^{22}$. Alcover comentaba la situación en Mallorca y Cataluña: en las islas Baleares sólo se utilizaba el nombre primitivo de patata; en cambio, en Cataluña, el uso de este vocablo era considerado minoritario, ya que según el filólogo «es diu generalment trumfa i en plural trumfos». Alcover explica esta noticia muchos años antes de que viese la luz el primer volumen del Diccionari Català-Valencià-Balear, en cuyos preparativos ya estaba trabajando desde 1900. Este diccionario saldría entre 1930 y 1962 y la voz «trumfa», que es la que nos interesa analizar, corresponde a uno de los últimos volúmenes. En ella, se considera que era el nombre que recibía la patata en las comarcas de Cerdanya, Ribes, Empordà, Gironès, Garrotxa, Cardona, Reus, Andorra, Vall d'Àneu, Sort, Pont de S., Castanesa, Tremp, Organyà, La Llitera, Balaguer y Priorat. Y se listaban las diferentes variedades del tubérculo convenientemente descritas y localizadas: trumfes bajanes, trumfa bufet, trumfa cega, trumfes de bolado, trumfa de l'abundància, trumfa de tabella y trumfa carabassar. El diccionario recoge asimismo sus derivados: trumfassa, trumfera, trumferar, trumfi y trumfo ${ }^{23}$. Asimismo, resulta reveladora la presencia en este diccionario de la voz «pataca» para designar la patata. Como hemos visto, la palabra no se hallaba presente en el diccionario de términos catalanes de 1839, mientras que en el Diccionario de la Real Academia Española servía para definir a la «patata de caña», es decir, al toupinambor francés. El Diccionario Catalán-Valenciano-Balear, en cambio, señalaba su utilización como sinónimo de «patata» en los lugares de Camp de Tarragona, Massalcoreig, Calasseit, Gandesa, Tortosa, Amposta, Valljunquera, Aiguaviva, Maestrat y Morella. Como en el caso de la «trumfa», se describen ahora las características de sus distintas variantes, que aquí nos limitamos a enunciar: pataca del cadup, pataca roja, pataca cacauera o de les set setmanes, pataca del bolado, pataca del bufet nano y pataca del bufet alt.

Contrasta esta proliferación de nombres - catorce si sumamos los de la trumfa y los de la pataca - con la austeridad y la importancia del factor culinario en la descripción de la voz patata: «tubèrcul de la planta Solanum tuberosum, molt usat en l'alimentació, condimentat de diferents maneres (patates frites, patates bullidles, greixera de patata, etc.)». Son muchos nombres y muchos matices para no ver reflejado en ellos un saber campesino popular profundamente arraigado.

El Atles Linguístic elaborado bajo la dirección de los filólogos Joan Veny y Lídia Pons, a partir de encuestas realizadas entre 1964 y 1975, muestra como las palabras trumfa y pataca aún eran utilizadas — y preferidas — en estas fechas por la población

22 Aunque cuando examinamos el atlas de donde ha entresacado la información, vemos que la palabra truffe se halla presente en la mayor parte del territorio francés.

23 El diccionario también recoge el significado de patata en la segunda acepción de la palabra «trufa», que situa en los Pirineos orientales y en Berga. 


\section{Mapa 1. Producción de patatas según Madoz (1845-50) y uso de las palabras «trumfa»y «pataca» según Veny y Pons (2008)}

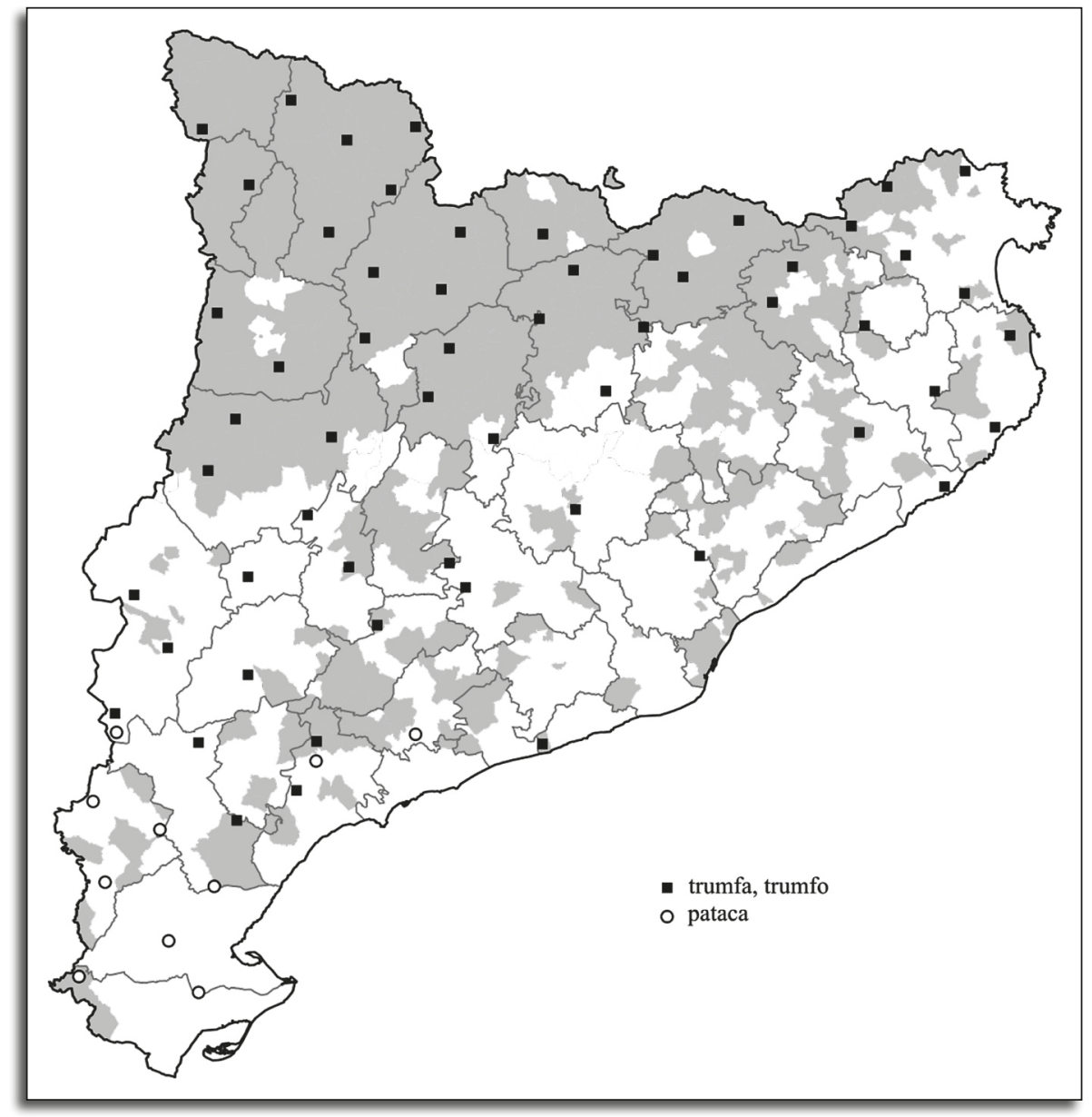

๑) Ricard García Orallo. Mapa elaborado a partir de Fàbrega (2017), que recoge los datos de Madoz, y del mapa reproducido en Veny y Pons (2008).

en una gran parte del territorio catalán (Veny, Pons, 2008). Pero, para nosotros, lo más revelador del mapa 1 es la coincidencia entre el área en la que sabemos el tubérulo se difundió tempranamente y el area donde los vecinos entrevistados señalaron la voz trunfa para identificar a la patata.

Mucho antes de la publicación del Atles, si bien coincidiendo con el período en que se realizaron las encuestas, el fenómeno ya había llamado la atención de algunos sociolinguistas. En 1976, Antoni Badía Margarit, uno de los mentores del Atles, lo 
interpretaba como prueba de la inmunidad, durante muchos años, de lo rural frente a lo urbano, con una idea especialmente interesante:

«Quisiera detenerme unos instantes en la situación de confluencia que acabo de mencionar (que se da, insisto, en las zonas en las que el termino «antiguo» - $\mathrm{y}$ antes exclusivo - es trumfa, término que hoy se encuentra en competencia con el «nuevo» de patata) a base de lo que yo mismo he podido observar en varios puntos de la comarca de la Garrotxa [provincia de Gerona], que me parece exponente de una situación más general. Allí, desde tiempo inmemorial, trumfa era la denominación peculiar. Hoy, se conocen y se emplean tanto trumfa como patata. Ahora bien, en vez de hacer sinónimos ambos términos, los campesinos de la comarca distinguen: trumfa se usa en todo lo que se refiera al cultivo (siembra, crecimiento, desarrollo, enfermedades, cosecha), mientras que patata se usa en todo lo que se refiera al producto (comercio, distribución y exportación, consumo, arte culinaria)» (Badía y Margarit, 1976).

En la actualidad, el Diccionario de la Gran Enciclopedia Catalana define la voz «trumfa» como la «aplicación rural, de forma alterada, de trufa a la patata», y «pataca» como una variante de la patata. Pero el matiz introducido por Badía permite ir un poco más allá. Al respecto, un trabajo académico reciente, realizado en 2013, en las lejanas comarcas del Priorat y del Baix Camp, parece confirmar que el caso de la Garrotxa analizado por él no era un caso aislado (Rehues Estivill, 2013). También allí nombraba diferentemente el tubérculo que se plantaba y el que se compraba. Una cosa parece bastante clara, fueron los compradores de patatas, y no sus productores quienes adoptaron la palabra que las élites utilizaron en sus escritos.

\section{A modo de conclusión}

Los viajeros de finales del siglo XVIII han señalado las primeras áreas catalanas donde se plantaron patatas. Todas las evidencias parecen ratificar la idea de que durante los años de la guerra contra Francia su producción se extendió por gran parte de Cataluña y que a mediados del siglo XIX su consumo había llegado a todas las clases sociales. Todo eso sucedió sin que haya quedado demasiado rastro en la documentación histórica. La hipótesis que hemos defendido en este trabajo parte de la idea, que las tesis elitistas habían rechazado de antemano que la payesía humilde, analfabeta pero experta en el saber agrario, pudo haber jugado desde el primer momento un papel importante y decisivo en ese proceso.

Los mismos argumentos que permiten imaginar al pequeño campesinado catalán como agente activo en el proceso de difusión de la patata, también pueden aplicarse a masoveros y a rabassaires en otros procesos innovadores - algunos de ellos silen- 
ciosos, otros más ruidosos - que impulsaron el crecimiento agrario catalán del siglo XVIII (Congost, Planas, Saguer, Vicedo, 2010). En el caso de las patatas, el silencio de los propietarios de las heredades es particularmente escandaloso. Ellos, que sabían leer y escribir, podían haber prestado atención a las noticias que llegaban procedentes de todo el mundo sobre la bondad del tubérculo y, siguiendo sus consejos y movidos por su afán de mejora, o por su sentimiento caritativo, factores ambos de los que alardeaban en sus escritos, habrían podido incluir la obligación del cultivo de las patatas en los contratos de masovería, pero no lo hicieron. ¿Debemos pues continuar explicando la historia como si lo hubiesen hecho? 


\section{Bibliografía}

Alcover, Joan (1914), Bolletí del Diccionari de la Llengua Catalana, volum. VIII, puede consultarse en: https://alcover.iec.cat

Allen, Robert (2004), Revolución en los campos. La reinterpretación de la revolución agrícola inglesa, Zaragoza, Prensas de la Universidad de Zaragoza/SEHA.

Amat i de Cortada, Rafael d' (1987), Calaix de Sastre, Barcelona, Barcelona-Curial, volums V y VIII.

BAHÍ, Joan Francisco (1820), “Memoria sobre los cultivos más económicos y fáciles de poner en práctica, y de un rendimiento seguro en los terrenos baldíos que se asignen por las Cortes a los soldados y marineros beneméritos de la patria”, Memorias de Agricultura y Artes, Publicado por orden de la Junta Nacional de Gobierno del Comercio de Cataluña, tomo 11, septiembre, pp. 97-114. https:// ddd.uab.cat/pub/memagrart/memagrart_a1820m9t11@bnc.pdf

BAHÍ, Joan Francisco (1815) “Observaciones sobre los abonos, particularmente del reyno mineral", Memorias de Agricultura y Artes, Publicado por orden de la Junta Nacional de Gobierno del Comercio de Cataluña, diciembre, pp. 245-260.

BAHÍ, Joan Francisco (1816) “Del cultivo de las patatas con respecto al sostenimiento y aumento de la población en España", Memorias de Agricultura y Artes, Publicado por orden de la Junta Nacional de Gobierno del Comercio de Cataluña, febrero, pp. 62-64.

BARBA I RocA, Manuel (1964), Memòries acadèmiques, Barcelona, Fundació Josep Massot i Palmés.

BARBA I RocA, Manuel (1991), El corregiment i partir de Vilafranca del Penedès a l'últim terç del segle XVIII. Resposes al qüestionari de Francisco de Zamora, Vilafranca del Penedès, Edicions del Museu de Vilafranca.

Bernat, Pasqual (2005), Mossèn Francesc Mirambell i Giol (1761-1822): naturalista i erudit del Lluçanès, Prats del Lliuçanès, Centre d'Estudis del Lluçanès.

Bernat, Pasqual (2008), Ciència, tècnica i agricultura a la Catalunya de la Il·lustració (1766-1821), Girona, Documenta Universitaria/Universista de Girona.

BroAD, John (2013), "Farmers and Improvement, 1780-1840”, en Hoyle, Richard W. (ed.), The Farmer in England, 1650-1980, London, Routledge.

Bourcelot, Henri (1966-2012), Atlas Linguistique et Ethnographique de la Champagne et de la Brie (ALCB), Paris, Éditions du C.N.R.S., vols. I-IV.

Bruneau, Charles (1932), «Les noms de la pomme de terre en Belgique romane », Études de dialectologie romane dédiées à la mémoire de Charles Grandgagnage, Genève, Slatkine Reprints, pp. 57-78. 
CAResmar, Jaume (1780), Discurso sobre la Agricultura, Comercio e Industria del Principado de Cataluña, Barcelona, Editorial Alta Fulla (edición a cargo de Ernest Lluch, 1997).

CERDÀ, Ildefons (1867), "Monografía estadística de la clase obrera de Barcelona en 1856", incluída como apéndice en Cerdà, Ildefons, Teoría general de la Urbanización y aplicación de sus principios y doctrinas a la Reforma y Ensanche de Barcelona, Madrid, Imprenta Española, vol. II.

Congost, Rosa (1989), "Presión demográfica, relaciones de clase y producción agrícola en la región de Gerona (1768-1862)”, Agricultura y Sociedad, 50, pp. 155-186.

Congost, Rosa (1990), Els propietaris i els altres, Vic, Eumo.

Congost, Rosa (2014), "Més enllà de les etiquetes. Reflexions sobre l'anàlisi dels grups socials humils. La regió de Girona (1770-1859)", Recerques, 68, pp. 165-191.

Congost, Rosa, Planas, Jordi, Saguer, Enric, Vicedo, Enric (2010), “¿Quien transformó la agricultura catalana? Los campesinos como actores del cambio agrario. Cataluña, siglos XVIII-XX”, en Robledo, Ricardo (ed.), Sombras del progreso. Las huellas de la historia agraria. Ramon Garrabou, Barcelona, Crítica, pp. 171-198.

Congost, Rosa, Ros, Rosa, SAguer, Enric (2016), "Beyond Life Cycle and Inheritance Strategies: The Rise of a Middling Social Group in an Ancien Régime Society (Catalonia, Eighteenth Century)", Journal of Social History, 49, 3, pp. 617-646. https://doi.org/10.1093/jsh/shv056

Congost, Rosa (2018), “La cuestión agraria en la España del siglo XIX”, en Carrillo, Germán y Cuño, Justo (comp.), Historia agraria y políticas agrarias en España y América Latina desde el siglo XIX hasta nuestros días, Madrid, Ministerio de Agricultura y Pesca, Alimentación y Medio Ambiente, pp. 249-294.

Corbella, Jacint, Gallegos, Àngels (2011), "Documentació a l'Acadèmia de Medicina de Barcelona sobre l'epifitia de les patates de 1845 a Catalunya", Gimbernat, 56, pp. 61-68.

D’Alembert, Jean Le Rond, Diderot, Denis (1750), Enclyclopédie, ou Dictionnaire raisonné de sciences, des arts et des métiers, Paris, Briasson, tome 13.

D’Alembert, Jean Le Rond, Diderot, Denis (1779). Enclyclopédie, ou Dictionnaire raisonné des sciences, des arts et des métiers, Genève, Pellet, tomes 26 et 34.

DAUZAT, Albert (1922), La géographie linguistique, París, Flammarion.

Demo, Edgardo, Ferrari, Maria Luisa (2015), “Crisi e nuove colture: il dibattito agronomico sulla patata tra XVIII e XIX secolo. Alcune considerazioni riguardanti l'Italia", en Ferrari Maria Luisa y Vaquero, Manuel (eds.), «Moia la carestia». La scarsità alimentare in età preindustriale, Bolonia, Il Mulino, pp. 325-341.

DuBuc, André (1953), « La culture de la pomme de terre en Normandie avant et depuis parmentier », Annales de Normandie, 1953, pp. 53-68. 
DuRAN, Montserrat (1997), "La introducción de los cultivos americanos en Cataluña (ss. XVI-XVIII)”, en Ctirzt, Jose Morilla, Gómez Pantoja, Joaquín L., Cressier, Patrice (eds.), Impactos exteriores sobre el mundo rural mediterráneo, Madrid, Ministerio de Agricultura, Pesca y Alimentación, pp. 289-305,

EARLE, Rebeca (2018), "Promoting Potatoes in Eigteenth-Century Europe", EighteenthCentury Studies, vol. 51, 2, pp. 147-162. https://doi.org/10.1353/ecs.2017.0057

FÀBreGA, Albert (2017), "La introducció i l'expansió de la patata i el blat de moro a Catalunya", Estudis d'Història Agrària, 28, pp. 13-46.

Fages de RomÀ, Narcís (1849), Aforismes Rurals, Figueres, Imprenta y Libreria de Gregorio Matas de Bodalles.

FeBVRE, Lucien (1940), «Les aliments: patate et pomme de terre », Annales d'Histoire Sociale, 2, pp. 135-136. https://doi.org/10.3406/ahess.1940.3036

FERNÁNDEZ GonZÁlEZ, Ángel (1994), “Las estrategias antifiscales en las sociedades campesinas tradicionales. Galicia, 1700-1840”, Hacienda Pública Española, monografia 1, Madrid, pp. 123-134.

GENTILCORE, David (2012), Italy and the potato: a history, Londres, Continuum.

Gibault, Georges (1912), Histoire des légumes, Paris, Librairie Horticole.

GilliÉron, Jules y Edmont, Edmond (1902-1920), Atlas linguistique de la France $(A L F)$, Paris, Honoré Champion.

Heras de Puig, Narcís (1853), "Sobre la multiplicación y cultivo de las patatas", La Granja, s.l.e.

La cuinera catalana, ó sia regles útils, fàcils, segures y económicas per cuynar bé: escullidas dels autors que millor han escrit sobre aquesta matèria (2008), Barcelona, Cossetània Edicions.

Iglésies, Josep (1964), Prefacio de Manuel Barba i Roca (1752-1822), Memòries acadèmiques, Barcelona, Fundació Josep Massot i Palmés.

KaWAGUCHI, Yuji (2017), "Pomme de terre 'potato' in French. A Geolinguistic Analysis of Lexical Variation”, Flambeau, vol. 43, pp. 38-52.

LABÈrniA, Pere (1839), Diccionari de la llengua catalana ab la correspondencia castellana, Barcelona, Estampa dels Hereus de la V. Pla

LABROUSSE, Ernest (1944), La crise de l'économie française à la fin de l'Ancien Régime et au debut de la Révolution, Paris, PUF.

Lluch, Ernest (1973), El pensament econòmic a la Catalunya, 1760-1840, Barcelona, Edicions 62.

Madoz, Pascual (1845-50), Diccionario geográfico-estadístico-histórico de España y sus posesiones de ultramar, Madrid, Establecimiento tipográfico de P. Madoz y L. Sagasti. 
Martínez Quintanilla, Pedro (1865), La Provincia de Gerona. Datos estadísticos, Girona, Imprenta F. Dorca.

MASPOnS y CAmarasa, Jaume (1907-1916), “Agricultura”, en Candi Carreras, Eugeni (ed.), Geografia General de Catalunya, , Barcelona, Editorial de Albert Martín, vol. 2.

Mirambell, Francesc (1816), "Noticias sobre agricultura por el Dr. D. Francisco Mirambell", Memorias de Agricultura y Artes, Publicado por orden de la Junta Nacional de Gobierno del Comercio de Cataluña, abril, p. 155-160.

Monlau, Pedro Felipe (1847), Elementos de higiene pública, Barcelona, Imprenta de D. Pablo Riera.

Moreno Claverías, Belén (2005), Consum i condicions de vida a la Catalunya Moderna. El Penedès, 1670-1790, Vilafranca del Penedès, Edicions i propostes Culturals Andana, S.L.

Morineau, Michel (1970), « La pomme de terre au XVIIIe siècle », Annales. Économies, Sociétés, Civilisations, 6, pp. 1767-1785. https://doi.org/10.3406/ ahess. 1970.422316

PalancA, David (2012), Introducción y generalización del cultivo y consumo alimentario y médico de la patata en el País Vasco, 1760-1860, Tesis Doctoral inédita, Universidad del País Vasco-EHU.

Parmentier, Antoine (1789). « Pomme de terre », en Rozier, Abbé, Cours complet d'agriculture théorique, pratique, économique, et de Médecine rurale et Vétérinaire ou Dicttionnaire Universel d'Agriculture, París, Hôtel Serpente, vol. VIII.

PÉrez SAMPER, M. de los Ángeles (2008), “La alimentación como signo de diversidad social: la encuesta de Zamora", Pedralbes, 28, pp. 649-672.

PiQueras HaBA, Juan (1992), “La difusión de la patata en España (1750-1850): el papel de las sociedades económicas y del clero rural", Ería, 27, pp. 80-89.

PonZ, Antoni (1788), Viage de España, Madrid, Viuda de Ibarra, Hijos y Compañía, vol. 14.

Rehues Estivill, Assumpció (2013), “Converses en un espai de frontera dialectal. Estudi sobre la transició dialectal a les fronteres comarcals del Priorat i del Baix Camp", Trabajo inédito de Final de Carrera, Universitat Oberta de Catalunya.

RozIER, Abbé (1781-1800), Cours complet d'agriculture théorique, pratique, économique, et de Médecine rurale et Vétérinaire ou Dicttionnaire Universel d'Agriculture, París, Hôtel Serpente (consultada asimismo la versión en castellano (1797-1803), Diccionario de Agricultura teórica-práctica y económica, y de medicina doméstica y veterinaria, Madrid, Imprenta Real).

Sabater, Ramon de (1853), "Cultivo alterno. Práctica de Gerona", Revista de L'I.A.C.S.I., Barcelona. 
Salaman, Radcliffe (1985), The History and Social Influence of the Potato, Cambridge University Press.

SANLlEHÍ, Maria Àngels (2014), Les respostes de la Val d'Aran als qüestionaris de Francisco de Zamora, Temp, Garsineu Edicions.

Serra de Manresa, Fra Valentí (1996), Els caputxins de Catalunya, de l'adveniment borbònic a la invasió napoleònica, Barcelona, Herder.

Serra, Roser, Ferrer, Llorenç (1985), "Un qüestionari de Francisco de Zamora (1789)", Estudis d'Història Agrària, 5, p. 139-207

Sobrado Correa, Hortensio (1996), “Transformaciones agrarias, estrategias hereditarias y crecimiento demográfico en las tierras lucenses, 1750-1860", Obradoiro de Historia Moderna, 5, pp. 7-40.

Sobrado Correa, Hortensio (2016), "El impacto del cultivo de la patata en el paisaje agrario y la economia rural de la Galicia anterior, siglos XVIII y XIX", comunicación presentada en el XV Congreso de Historia Agraria de la SEHA, Lisboa, 27-30 de enero de 2016, https://docplayer.es/21275626-El-impactodel-cultivo-de-la-patata-en-el-paisaje-agrario-y-la-economia-rural-de-la-galiciainterior-siglos-Xviii-xix.html

SPITZER, Leo (1911), “Die Namengebung bei neuen Kulturpflanzen im Französischen”, Wörter und Sachen, IV, pp. 122-165.

Veny i Clar, Joan, Pons Griera, Lídia (2008), Atles linguístic del domini català, Barcelona, Institut d'Estudis Catalans, volumen IV.

Vicens Vives, Jaume, Llorens, Montserrat (1980), Industrials i polítics (segle XIX), Barcelona, Editorial Vicens Vives (edición original, 1958).

Vila, Pep (2000), La litúrgia del menjar a les terres gironines, Girona, Diputació de Girona.

VILAR, Pierre (1962), La Catalogne dans l'Espagne Moderne, París, S.E.V.P.E.N., vol. 2.

VILAR, Pierre (1975), "Un fonds catalan aux Archives Nationales Françaises », Miscel-lània Pau Vila. Biografia, Bibliografia, Treballs d'homenatge, Granollers, Editorial Montblanc-Martin, pp. 501-519.

Young, Arthur (1909) Travels in France during 1787, 1788, 1789 [1792], Londres, Georges Bell and sons.

Young, Arthur (1787), Viatge a Catalunya, Barcelona, Ariel.

ZAmora, Francisco de (1973), Diario de los viajes hechos en Cataluña, Barcelona, Curial, (edición original, 1787). 